\title{
Correction to: Investigation of MBE-Growth of Mid-Wave Infrared $\mathrm{Hg}_{1-x} \mathrm{Cd}_{x} \mathrm{Se}$
}

\author{
I. MADNI ${ }^{1,},{ }^{1,2}$ G.A. UMANA-MEMBRENO,${ }^{1}$ W. LEI, ${ }^{1}$ and L. FARAONE ${ }^{1}$
}

1.-School of Electrical, Electronic and Computer Engineering, The University of Western Australia, Crawley, WA 6009, Australia. 2.—e-mail: imtiaz.madni@gmail.com

\section{Correction to:}

Journal of ELECTRONIC MATERIALS,

Vol. 47, No. 10, 2018

https://doi.org/10.1007/s11664-018-6565-2

In the original article, G. A. Umana-Membreno's name is incorrect. It is corrected as reflected here. 